\title{
Study of Renal Profile in Babies with Perinatal Asphyxia in a Tertiary Care Hospital: A Prospective Case Control Study
}

\author{
Roy $\mathbf{B}^{1}$, Mondal $\mathbf{G}^{2}$ \\ ${ }^{1}$ Dr. Banasree Roy, MBBS, DCH, MD. RMO cum Clinical \\ Tutor, Dr. B.C.Roy Postgraduate Institute of Paediatric \\ Sciences, Kolkata 70054, West Bengal, India, ${ }^{2} \mathrm{Dr}$. \\ Gobinda Mondal, MBBS, MD. Assistant Professor, \\ Department of Paediatric Medicine, Burdwan Medical \\ College. West Bengal, India.
}

\section{Introduction}

A ccording to World Health Organization failure to initiate or sustain respiration after birth has been defined as criteria for the diagnosis of asphyxia ${ }^{1}$. According to National Neonatology Forum $5-10 \%$ of all babies in India suffer from perinatal asphyxia².

Asphyxia at patho-physiological level, is the simultaneous combination of both hypoxia and hypoperfusion which impairs tissue gas exchange leading to tissue acidosis. Perinatal asphyxia will occur due to gas exchange and oxygen transportation disorders at birth that result lack of oxygen supply and difficulties in carbon - di-oxide expiration ${ }^{3}$. This lack of oxygen supply in brain gives rise to hypoxic ischaemic injury to central nervous system; the clinical manifestation of this injury is termed as hypoxic ischaemic encephalopathy.

Cardiac output attempt to maintain blood flow to vital organ as heart, central nervous system, and also reduce blood flow to another organ like kidney, gastrointestinal and the other peripheral organ ${ }^{3}$. Almost any organ can be affected, but the brain, myocardium, kidneys and bowel appears to be most sensitive to severe damage ${ }^{4}$. Renal system is involved in $50 \%$ of the cases. Conversely, perinatal asphyxia producing ischemia is the commonest cause of renal failure in neonates ${ }^{5,6}$. The most common form of Acute Kidney Failure in neonates is prerenal failure which is due to renal hypoperfusion or ischemia ${ }^{7}$. Prerenal failure may result in intrinsic kidney failure if not treated promptly. The kidneys of neonates are particularly susceptible to hypoperfusion, because of

\author{
Address for correspondence \\ Dr. Banasree Roy \\ C/o Pijush Kanti Roy, Milannagar, \\ P.O. Kanchrapara, Dist 24 Parganas (North), \\ Pin 743145, West Bengal, India. \\ E-mail: drbr1978@rediffmail.com
}

\begin{abstract}
Introduction: Perinatal asphyxia is one of the important causes of preventable cerebral injury occurring in the neonatal period. Kidney is one of the most commonly affected organs leading to renal functional abnormality and blood electrolyte imbalance. This was a prospective case control study done in the NICU and neonatal unit at a tertiary care hospital. The objective of this study were to detect renal functional abnormality and electrolyte imbalance (sodium and potassium) among babies with perinatal asphyxia and to correlate severity and type of renal involvement with degree of asphyxia. Materials and Methods: Thirty two neonates for perinatal asphyxia and 32 babies selected randomly from non asphyxiated babies for the control group. Blood samples were taken for measurement of serum urea, creatinine, sodium and potassium levels on $1^{\text {st }}$ and $3^{\text {rd }}$ day of life. If any abnormality detected, values were repeated every alternate days till it become normal. Results: There were total 32 cases (asphyxiated). Among 32 cases 14 (43.75 $\%)$ had elevated levels of urea and creatinine on day 1 [Mean urea $(43.21 \pm 23.08)$, creatinine $(1.14 \pm 0.57)$ ], $18(56.25 \%)$ had elevated levels of urea and creatinine on day 3.Mean urea (58.06 \pm $28.52)$ and creatinine $(1.24 \pm 0.5)$ were significantly higher on day 3 ( $p$ value $<0.05)$ in study group as compared to control. Mean urea and creatinine levels showed increasing trend with degree of severity of hypoxic ischaemic encephalopathy. Eighteen babies with perinatal asphyxia developed renal failure (56.25\%). 18 had Hyponatremia on day $1(56.25 \%), 3$ of them had value $<125$ meq /l. Conclusion: Among study cases significantly higher values of urea and creatinine were found than controls. The values were positively correlated to the degree of asphyxia. Though, mean sodium and potassium level was within the normal limit, the value of potassium was higher among cases than controls.
\end{abstract}

Key words: Perinatal asphyxia, Hypoxic Ischaemic Encephalopathy, Renal failure.

\section{How to cite this article?}

Banasree Roy, Gobinda Mondal. Study of Renal Profile in Babies with Perinatal Asphyxia in a Tertiary Care Hospital: A Prospective Case Control Study. J Nepal Paediatr Soc 2013;33(3):206-212. 
the physiologic characteristics of neonatal kidneys; high renal vascular resistance, high plasma renin activity, low glomerular filtration rate, decreased intercortical perfusion, and decreased reabsorption of sodium in the proximal tubules are the susceptibilities of the kidneys in the first days of a neonate ${ }^{8}$. Thus, newborn infants are vulnerable to acute tubular necrosis or cortical necrosis.

Acute renal failure (ARF) is defined as the rapid elevation in the concentration of blood urea nitrogen (BUN), creatinine, and other cellular waste products in the blood resulting from diminished glomerular filtration rate (GFR) in the kidney ${ }^{9}$. In term babies, the concentration of serum creatinine normally rises somewhat in the first 24 to 36 hours after birth, subsequently decreasing and stabilizing at about $0.4 \mathrm{mg} / \mathrm{dL}(35.4 \mathrm{mcmol} / \mathrm{L})$ by 5 days of age ${ }^{10}$. A clearly elevated value beyond the normal range indicates decreased glomerular function. Urine output is another key indicator of renal function. Commonly, ARF is suspected when oliguria is present, defined as a period during which urine output is less than $0.5 \mathrm{~mL} / \mathrm{kg}$ per hour ${ }^{11}$. Renal involvement is frequent in neonates with perinatal asphyxia, which correlates with the severity of neurological damage. Renal failure presents as oliguria and, during recovery, as highoutput tubular failure, leading to significant water and electrolyte imbalances. In one study it has been shown hyponatremia and hypocalcaemia developed early and simultaneously and the decrease in their serum levels was directly proportional to each other and to the degree of asphyxia. Though, mean potassium level was within the normal limit, the value was higher among cases than controls and directly proportional to asphyxia ${ }^{12}$.

Early recognition of acute renal failure (ARF) in babies with hypoxic ischemic encephalopathy (HIE) is essential to facilitate appropriate fluid and electrolyte management as stable biochemical milieu is vital.

Objectives of study were to detect renal functional abnormality and electrolyte imbalance (sodium and potassium) among babies with perinatal asphyxia and to correlate severity and type of renal involvement with degree of asphyxia.

\section{Materials and Methods}

The study was undertaken in the Neonatal unit and NICU of a tertiary care Hospital from August 2007- April 2008 for a 9 month period. The protocol of the study was approved by the Institute Ethics Committee and written informed consent was obtained from the parents of each neonate. All neonates were resuscitated as per Neonatal Resuscitation Program (NRP) guidelines.

Inclusion criteria were apgar score $\leq 6$ at 1 minute and gestational age of $\geq 37$ weeks.
Exclusion criteria were babies with congenital malformation, gestational age $<37$ wks, babies who developed early or late onset sepsis, babies who developed neonatal hyperbilirubinemia and babies born with meconium stained liquor.

Babies with perinatal asphyxia are staged by Sarnat and Sarnat Scoring System ${ }^{13}$. Gestational age was determined by expanded new Ballard score. Those babies who developed early or late onset sepsis as judged by clinical examination followed by laboratory values like septic screening, chest $\mathrm{x}$-ray, blood culture, CSF study etc were excluded. Babies who developed neonatal hyperbilirubinemia were excluded as values of Creatinine modified when detected by Jaffe's method in hyperbilirubinemia.

After admission appropriate measures were taken for initial stabilization for asphyxiated babies. Detailed history and systemic examinations were recorded in a pre-designed proforma. Severely affected babies were given IV fluids, oxygen initially. Patients who were stable clinically and lab values are normal, gavage or katori spoon feeding started with expressed breast milk and as the condition improves shifted to breast feeding. Control group was allowed breast feeding. All the babies of case and control groups were given Injection Vitamin $\mathrm{K} 1 \mathrm{mg}$.

Disposable plastic urine bag was used to collect urine sample for different tests \& for measurement of 24 hrs urine output. Urine samples were sent for presence of protein, RBC, casts and to determine Specific gravity on $1^{\text {st }}$ day and $3^{\text {rd }}$ day. If any abnormality was detected further tests were done every alternate day. Blood samples were taken from peripheral veins for measurement of serum urea, creatinine, and sodium, potassium levels on $1^{\text {st }} \& 3^{\text {rd }}$ day. If any abnormality detected, values were repeated every alternate days till it became normal. Serum urea estimation was done by semi-auto analyzer using Urea kit following Mod. Berthelot method. Serum Creatinine was estimated by semi-auto analyzer using Creatinine kit following Mod. Jaffe's Kinetic method. Serum sodium \& potassium were measured in automatic electrolyte analyzer using ion selective electrode technology. In some of the cases who developed renal failure Fractional Excretion of Sodium (FENa) \% were estimated to determine intrinsic type of renal failure. FENa $=100 \times(\mathrm{U} \mathrm{Na} \times \mathrm{P} \mathrm{Cr}) /(\mathrm{P} \mathrm{Na}$ $x \cup \mathrm{Cr}$ ).

Criteria for renal failure was defined as urine output: $<0.5 \mathrm{ml} / \mathrm{kg} / \mathrm{hr}$ (Oliguria), blood urea: $>40 \mathrm{mg} / \mathrm{dl}$, serum creatinine: $>1 \mathrm{mg} / \mathrm{dl}$ and presence of significant hematuria or proteinuria.

Any three of these criteria on day 3 of life when fulfilled, is to be considered as indication of renal failure ${ }^{15}$. 


\section{Statistical Analysis}

$Z$ test for mean is applied for comparison between cases and controls. We have applied t-test of Mean to compare between above groups. A $p$ value of $<0.05$ was considered as statistically significant.

\section{Results}

We had a total of 32 study subjects and 32 in control groups. Among cases $56.25 \%$ were males and $43.75 \%$ were females. There were $65.62 \%$ males and $34.38 \%$ were females in the control group. Mean birth weight in study group was $2.58 \pm 0.45 \mathrm{~kg}$ and in control group $2.60 \pm 0.30 \mathrm{~kg}$. In our study, 9 patients were HIE 3,13 in HIE 2 and 10 in HIE 1 category. 7 patients needed resuscitation beyond 5 minutes. 15 patients had Apgar $\leq 4$ at 5 minutes.

It indicated that mean urea and creatinine values were higher in study group as compared to control. Statistical analysis showed this to be significant $(p<0.05)$ for both urea and creatinine. The values were on higher side on $3^{\text {rd }}$ day as compared to day 1 .

According to staging HIE 1, 2 and 3 (Sarnat and Sarnat) the levels of blood urea and creatinine rose both on day 1 and 3 .

Mean urea level on day 1 increased when hypoxic ischaemic encephalopathy staging was increased, though this correlation was not statistically significant ( $r$ value $=0.3086, p>0.05)$. Day 3 urea level rose significantly when HIE staging increased $(r=0.5334$, $p<0.05)$.

Mean creatinine level on day 1 was found to be increased with higher HIE grading and correlation coefficient value was significant $(r=0.4471, p<0.05)$. Day 3 creatinine level rose significantly with increase in HIE stage $(r=0.6033, p<0.05)$.

On day 1 and 3 (Table 3 ) mean sodium level increased in control group than study group, whereas mean potassium value was higher in the study group. These changes were statistically significant $(p<0.05)$

Variation in serum sodium levels between HIE 1 and HIE 2 was not significant, but noticeable change of mean sodium level was observed in HIE 3 in comparison to stage 1 and 2 . No noticeable change of potassium level was seen on day 1 with different stages of HIE. But the mean value of potassium on day 3 increased proportionately with increase in grade of HIE. Day 3 mean sodium value showed significant negative correlation $(r=-0.5227, p<0.05)$ with degree of HIE. Day 3 mean potassium levels showed positive correlation with increase in degree of asphyxia but was not statistically significant $(r=0.3350, p>0.05)$.

Urinary parameters studied on day 1 and 3 are as shown in Table -5 which revealed less mean volume of 24 hour urine in study group as compared to control. The mean urine volume gradually decreased as $\mathrm{HIE}$ grading increased. On Day 1 urine specific gravity did not show much difference between study and control population, as well as in between different HIE stages. Out of total cases $9.3 \%$ showed presence of protein and $3.1 \%$ showed RBC in urine specimen. Mean 24 hours urine volume showed negative correlation with HIE stages which was statistically significant $(r=-0.4661$, $p<0.05$ ). Mean urine specific gravity also showed negative correlation with increase in HIE stage, though not significant ( $r=-0.2201, p>0.05)$. On Day $3,18 \%$ of cases showed proteinuria and $12.5 \%$ patients showed $\mathrm{RBC}$ in urine sample. The values of mean 24 hours urine volume decreased when HIE grade increased and negative correlation noted which was significant $(r=-0.4437, p<0.05)$. Mean specific gravity of urine revealed negative correlation with HIE grading but was not significant $(r=-0.2172, p>0.05)$.

It was found that mean values of urea, creatinine, and potassium was much higher in asphyxiated babies with renal failure than other groups. But little variation was observed in between babies with birth asphyxia without renal failure and in control group as shown in table 6.

Mean values of sodium was lower in asphyxiated babies with renal failure. In babies with birth asphyxia without renal failure sodium level was higher than babies with renal failure but lower in comparison to control group. Urine volume was showing a rising value from babies with renal failure verses without renal failure and control group.

Table 1: Blood Urea and Creatinine levels on day 1 and 3 in study and control Groups

\begin{tabular}{|l|c|c|c|}
\hline & $\begin{array}{c}\text { Study Group N=32 } \\
\text { Mean } \pm \text { SD }\end{array}$ & $\begin{array}{c}\text { Control Group N=32 } \\
\text { Mean } \pm \text { SD }\end{array}$ & $\begin{array}{c}\mathbf{z} \text { test for mean } \\
(\boldsymbol{p} \text { value })\end{array}$ \\
\hline Blood Urea Day 1 $(\mathrm{mg} / \mathrm{dl})$ & $43.21 \pm 23.08$ & $28.06 \pm 4.08$ & $3.659(<0.05)$ \\
\hline Serum Creatinine Day 1 $(\mathrm{mg} / \mathrm{dl})$ & $1.14 \pm 0.57$ & $0.73 \pm 0.11$ & $3.9001(<0.05)$ \\
\hline Blood Urea Day 3 $(\mathrm{mg} / \mathrm{dl})$ & $58.06 \pm 28.52$ & $28.46 \pm 3.58$ & $5.825(<0.05)$ \\
\hline Serum Creatinine Day 3 $(\mathrm{mg} / \mathrm{dl})$ & $1.24 \pm 0.5$ & $0.73 \pm 0.09$ & $5.679(<0.05)$ \\
\hline
\end{tabular}


Table 2: Urea and Creatinine levels in relation with HIE Staging

\begin{tabular}{|c|c|c|c|c|}
\hline \multirow{2}{*}{} & \multicolumn{2}{|c|}{ Blood Urea $(\mathrm{mg} / \mathrm{dl})$} & \multicolumn{2}{c|}{ Serum Creatinine ( mg/dl) } \\
\cline { 2 - 5 } & Mean \pm SD & Mean \pm SD & Mean \pm SD & Mean \pm SD \\
\cline { 2 - 5 } & Day 1 & Day 3 & Day 1 & Day 3 \\
\hline Study Group & $43.21 \pm 23.08$ & $58.06 \pm 28.52$ & $1.14 \pm 0.57$ & $1.24 \pm 0.5$ \\
\hline HIE 1 $(n=9)$ & $37.11 \pm 23.24$ & $40.22 \pm 25.23$ & $0.86 \pm 0.2$ & $0.83 \pm 0.33$ \\
\hline HIE 2 $(n=13)$ & $38.38 \pm 15.48$ & $54.38 \pm 20.11$ & $1.05 \pm 0.51$ & $1.23 \pm 0.40$ \\
\hline HIE 3 $(n=10)$ & $55 \pm 28.46$ & $78.9 \pm 29.59$ & $1.52 \pm 0.70$ & $0.49 \pm 0.09$ \\
\hline Control Group & $28.06 \pm 4.08$ & $28.46 \pm 3.58$ & $0.73 \pm 0.11$ & $0.73 \pm 0.09$ \\
\hline
\end{tabular}

Table 3: Correlation of levels of urea and creatinine with HIE staging

\begin{tabular}{|c|c|c|c|c|}
\hline & Day 1 & $p$-value & Day 3 & p-value \\
\hline S. Urea & 0.3086 & $>0.05$ & 0.5334 & $<0.05$ \\
\hline S. Creatinine & 0.4471 & $<0.05$ & 0.6033 & $<0.05$ \\
\hline
\end{tabular}

Table 4: Comparison of Serum Sodium and Potassium values on day 1 and day 3

\begin{tabular}{|l|c|c|c|}
\hline & $\begin{array}{c}\text { Study Group } \\
\text { Mean } \pm \text { SD }\end{array}$ & $\begin{array}{c}\text { Control Group } \\
\text { Mean } \pm \text { SD }\end{array}$ & $\begin{array}{c}\text { z test for mean } \\
(p \text {-value })\end{array}$ \\
\hline $\begin{array}{l}\text { Serum Sodium (meq /L) } \\
\text { Day 1 }\end{array}$ & $132.78 \pm 6.9$ & $136.65 \pm 2.08$ & $3.037(<0.05)$ \\
\hline Serum Potassium Day 1 (meq/L) & $5.14 \pm 1.45$ & $3.99 \pm 0.36$ & $4.354(<0.05)$ \\
\hline Serum Sodium Day 3 (meq /L) & $132.15 \pm 4.74$ & $136.43 \pm 2.44$ & $4.541(<0.05)$ \\
\hline Serum Potassium Day 3 (meq/L) & $5.24 \pm 1.39$ & $4.009 \pm 0.38$ & $4.832(<0.05)$ \\
\hline
\end{tabular}

Table 5: Serum Sodium and Potassium values in relation with HIE staging

\begin{tabular}{|c|c|c|c|c|}
\hline & \multicolumn{2}{|c|}{ Serum Sodium } & \multicolumn{2}{c|}{ Serum Potassium } \\
\cline { 2 - 5 } & $\begin{array}{c}\text { Day 1 } \\
\text { Mean } \pm \text { SD }\end{array}$ & $\begin{array}{c}\text { Day 3 } \\
\text { Mean } \pm \text { SD }\end{array}$ & $\begin{array}{c}\text { Day 1 } \\
\text { Mean } \pm \text { SD }\end{array}$ & $\begin{array}{c}\text { Day 3 } \\
\text { Mean } \pm \text { SD }\end{array}$ \\
\hline Study Group & $132.78 \pm 6.9$ & $132.15 \pm 4.74$ & $5.14 \pm 1.45$ & $5.24 \pm 1.39$ \\
\hline HIE 1 & $134.11 \pm 6.91$ & $135.22 \pm 3.66$ & $5.22 \pm 1.44$ & $4.37 \pm 0.79$ \\
\hline HIE 2 & $134.4 \pm 5.97$ & $132.53 \pm 5.50$ & $4.97 \pm 1.10$ & $5.57 \pm 1.83$ \\
\hline HIE 3 & $129.5 \pm 7.53$ & $128.9 \pm 1.96$ & $5.28 \pm 1.94$ & $5.60 \pm 0.77$ \\
\hline Control Group & $136.65 \pm 2.08$ & $136.43 \pm 2.44$ & $3.99 \pm 0.36$ & $4.0 \pm 0.38$ \\
\hline
\end{tabular}

Table 6: Urinary Values correlated with HIE staging on day 1 and day 3

\begin{tabular}{|l|c|c|c|c|}
\hline & $\begin{array}{c}\text { Urine Vol in 24 hrs (ml) } \\
\text { Mean } \pm \text { SD }\end{array}$ & $\begin{array}{c}\text { Specific Gravity } \\
\text { Mean } \pm \text { SD }\end{array}$ & $\begin{array}{c}\text { Protein } \\
\text { No (\%) }\end{array}$ & $\begin{array}{c}\text { RBC } \\
\text { No (\%) }\end{array}$ \\
\hline Study Group D 1 & $38.59 \pm 11.37$ & $1.0134 \pm 0.0028$ & $3(9.3)$ & $1(3.1)$ \\
\hline HIE 1 & $46.66 \pm 10$ & $1.0143 \pm 0.0023$ & 0 & 0 \\
\hline HIE 2 & $37.30 \pm 8.56$ & $1.0138 \pm 0.0029$ & 0 & 0 \\
\hline HIE 3 & $33 \pm 12.51$ & $1.0127 \pm 0.0033$ & 3 & 0 \\
\hline Control Group D1 & $78.12 \pm 19.03$ & $1.014 \pm 0.002$ & 0 & $4(12.5)$ \\
\hline Study Group D 3 & $52.18 \pm 18.79$ & $1.0132 \pm 0.0026$ & $5(15.6)$ & 0 \\
\hline HIE 1 & $62.77 \pm 11.75$ & $1.0143 \pm 0.0027$ & 0 & 0 \\
\hline HIE 2 & $53.07 \pm 17.74$ & $1.013 \pm 0.0025$ & 1 & 4 \\
\hline HIE 3 & $41.5 \pm 20.82$ & $1.0128 \pm 0.0028$ & 4 & 0 \\
\hline Control Group D3 & $82.34 \pm 13.19$ & $1.014 \pm 0.0022$ & 0 & \\
\hline
\end{tabular}


Table 7: Urinary and biochemical parameters on day 3

\begin{tabular}{|l|c|c|c|c|c|c|}
\hline & $\mathbf{N}$ & Urea (mg/dl) & $\begin{array}{c}\text { Creatinine } \\
(\mathbf{m g} / \mathbf{d l})\end{array}$ & $\begin{array}{c}\text { Sodium } \\
(\mathbf{m e q} / \mathbf{L})\end{array}$ & $\begin{array}{c}\text { Potassium } \\
(\mathbf{m e q} / \mathbf{L})\end{array}$ & $\begin{array}{c}\text { Urine volume } \\
(\mathbf{m l})\end{array}$ \\
\hline $\begin{array}{l}\text { Asphyxiated babies With renal } \\
\text { failure }\end{array}$ & 18 & $78.44 \pm 21.58$ & $1.62 \pm 0.31$ & $130.94 \pm 4.80$ & $6.03 \pm 1.33$ & $44.44 \pm 19.26$ \\
\hline $\begin{array}{l}\text { Asphyxiated babies with no renal } \\
\text { failure }\end{array}$ & 14 & $31.85 \pm 3.99$ & $0.74 \pm 0.10$ & $133.71 \pm 4.33$ & $4.22 \pm 0.59$ & $62.14 \pm 13.25$ \\
\hline Control & 32 & $28.46 \pm 3.58$ & $0.73 \pm 0.09$ & $136.43 \pm 2.44$ & $4.00 \pm 0.38$ & $82.34 \pm 13.19$ \\
\hline
\end{tabular}

Table 8: Comparison in babies with renal failure vs without renal failure and control

\begin{tabular}{|c|c|c|c|}
\hline \multicolumn{2}{|c|}{$\begin{array}{l}\text { Asphyxiated babies with renal failure vs Asphyxiated } \\
\text { babies without renal failure }\end{array}$} & \multicolumn{2}{|c|}{ Asphyxiated babies with renal failure vs control } \\
\hline Urea & $p<0.001$ & Urea & $p<0.001$ \\
\hline Creatinine & $p<0.001$ & Creatinine & $p<0.001$ \\
\hline Sodium & $p=0.71$ & Sodium & $p=0.001$ \\
\hline Potassium & $p=0.004$ & Potassium & $p<0.001$ \\
\hline Urine volume & $p=0.176$ & Urine volume & - \\
\hline
\end{tabular}

\section{Discussion}

In this study blood urea and creatinine values were significantly higher in asphyxiated babies in comparison to controls both in day 1 and day 3 . In a study by Anu Aggarwal ${ }^{14} \mathrm{et}$ al in 2005 it was found that serum urea and creatinine values were significantly higher on day 4 but not on day 2. In our study significant positive correlation found on day 3 urea, creatinine values with increase severity of birth asphyxia. We found $56.25 \%$ babies developed elevated urea \& creatinine levels on day 3. G Jayashree ${ }^{15}$ et al found $43 \%$ of asphyxiated babies had acute renal failure. But they did not find any significant correlation between Apgar score and development of renal failure, rather a significant relationship seen between hypoxic ischaemic encephalopathy and acute renal failure. In a study by B D Gupta ${ }^{16}$ et al found $33 \%$ of asphyxiated babies developed renal failure. In their study biochemical derangements correlated well with Hypoxic ischaemic stage and Apgar score. Ellya Nova Lubis $^{3}$ et al found mean urea and creatinine levels are significantly higher in asphyxiated babies.

In a study by Lopez Dominquez $\mathrm{O}^{17}$ et al among 76 patients with birth asphyxia $27 \%$ developed acute renal failure. In the population with acute renal failure of renal type perinatal asphyxia was clinically worse. Bashir A Itoo ${ }^{18}$ et al of Saudi Arabia found $53 \%$ of severe hypoxic ischaemic encephalopathy babies developed acute renal failure. In the moderate HIE groups only $22 \%$ had acute renal failure and none in mild HIE. Mortality rate was $37.5 \%$ among severe HIE group whereas no death was there in mild and moderate HIE.

In our study, Day 1 and Day 3 mean 24 hours urine volume was significantly lower than the control group. Also the mean urine volume was gradually decreasing with increased severity of birth asphyxia and it was statistically significant. We found $56.25 \%$ babies with birth asphyxia had elevated blood urea and creatinine levels on day 3 . Among these $21.87 \%$ had oliguria. In the oliguric group 4 cases $(57.15 \%)$ belonged to hypoxic ischaemic encephalopathy (HIE) stage 3, 3 cases $(42.85 \%)$ belonged to HIE stage 2 and none of HIE stage 1. Four (57.14\%) cases found to have persistently elevated levels of urea and creatinine on day $5 ; 2$ cases $(28.57 \%)$ expired, one on day 4 and other on day 6 . One case $(14.28 \%)$ had elevated urea and creatinine levels on day 7 . All cases of oliguria had normal urine volume by day 5 . So here overall prognosis of patients with oliguric renal failure is bad, also oliguric type of renal failure mainly associated with severe birth asphyxia; though statistical analysis is not significant. In a study by M. Gary Karlowicz ${ }^{19}$ et al $25 \%$ of asphyxiated neonates developed oliguria and $15 \%$ was anuric. BD Gupta et al in their study found $22 \%$ cases with oliguria, among those who developed renal failure. They found urinary output slightly less in neonates with severe birth asphyxia but statistically insignificant. In this study no neonate remained oliguric by day 4- 6 of life. Babies with oliguric renal failure had higher mortality $(42.8 \%)$ rate. In the study by Jayashree et $\mathrm{al}^{14} 69.2 \%$ of acute renal failure patients had oliguria and oliguric patients had poorer prognosis. Pejović $\mathrm{B}^{20}$ et al in their study found $64 \%$ of neonates with perinatal asphyxia developed oliguric renal failure. Most of them $(65 \%)$ had severe perinatal asphyxia. In oliguric newborns with severe asphyxia the outcome was fatal (31\%). Fernando Olavarria ${ }^{21}$ et al in one study evaluated renal function in asphyxiated neonates found that 10 cases among total 21 study subjects had oliguric renal failure, prerenal type as it was corrected promptly with volume expansion. In 9 cases urine volume and all other biochemical parameters found unaltered and comparable with control group. 
D Bourchier ${ }^{22}$ arranged this study and found that among 31 cases with severe birth asphyxia 24 developed oliguria and 18 of them had persisted oliguria. Poor outcome was significantly related with the degree of oliguria. J M Perlman and E D Tack ${ }^{23}$ in their study found birth asphyxia babies those with persistent oliguria had evidence of HIE clinically. Twenty three percent cases had transient oliguria on $1^{\text {st }}$ day which increased to normal value on $3^{\text {rd }}$ day of life. Mortality rate was $92 \%$ among them. Significant association was observed with oliguria and clinical stages of hypoxic ischaemic encephalopathy. In the study by P K Misra ${ }^{24}$ et al on patients with symptomatic asphyxia found all patients having oliguria and not responding to fluid challenge. This condition was associated with very high mortality. $S$ Kaur et al. ${ }^{25}$ evaluated glomerular and tubular function in neonates with perinatal asphyxia at Government Medical College and Hospital, Chandigarh, India during September 2006 to April 2007. Among 36 neonates Acute Kidney Injury (AKI) developed in 9.1\% (1/11) infants with moderate asphyxia and $56.0 \%(12 / 25)$ infants with severe asphyxia, making a total incidence of $41 \cdot 7 \%$. AKI persisted in $16.6 \%$ neonates at 96 hours of life. Ten neonates $(27 \cdot 7 \%)$ had serum creatinine levels $>1.5$ $\mathrm{mg} / \mathrm{dl}$. In a study by Varma $\mathrm{V}$ et al ${ }^{26}$ on 45 asphyxiated neonates evaluation was carried out to determine status of basic biochemical and haematological parameters in asphyxiated babies and their relationship with Apgar score, degree of HIE and development of ARF. In the study, Mean values of electrolytes showed no significant difference among cases and controls as well as in HIE stages. Highly significant rise was seen in serum urea and creatinine values on day 3 in asphyxiated babies with ARF compared to those without ARF. Similar rise was seen in stage II and III HIE on comparison with stage I HIE.

\section{Conclusion}

The level of urea and creatinine increased with severity of birth asphyxia. Oliguria was associated in some cases and it indicated a poorer prognosis. Hyponatremia is one of the complications of birth asphyxia which may or may not be associated with renal failure. Serum sodium level decreased as the severity of asphyxia increased. There was no significant difference in serum potassium level among the cases of birth asphyxia without renal failure and controls. So prompt detection and early supportive management of renal failure in asphyxiated babies is important.

\footnotetext{
Acknowledgements: None

Funding: None

Conflict of Interest: None

Permission from IRB: Yes
}

\section{References}

1. Spector J M,Daga S. Preventing those so called stillbirths. Bulletin of the World Health Organisation April 2008;86:241-320.

2. D.K.Guha. Perinatal asphyxia, In :Neonatal Asphyxia, Resuscitation and Beyond; Jaypee, $2^{\text {nd }}$ edition 2008; 8

3. Lubis E N, Yanda S, Akbar K, Tjipta G D, Aldy D. The effect of neonatal asphyxia on renal function. Paediatr Indones 2001;41:175-179.

4. Malcolm Levene: Birth asphyxia, In: Forfar \& Arneil's Textbook of Pediatrics; Churchill Livingstone, $6^{\text {th }}$ edition 2003; 197.

5. Chevalier RL, Campbell F, Noorman A. Prognostic factors in neonatal acute renal failure. Pediatrics 1984;74:265-72.

6. Guinard JP. Renal functions in new born infant. Pediatr Clin Am 1982;29:777-89.

7. Friedlich PS, Evans JR, Tulassay T, Seri I. Acute and chronic renal failure. In: Taeusch HW, Ballard RA, Gleason CA. Avery's diseases of the newborn. 8th ed. Philadelphia Elsevier Saunders; 2005. p. 1298-305

8. Mathur NB, Agarwal HS, Maria A. Acute renal failure in neonatal sepsis. Indian J Pediatr 2006;73:499502.

9. Norman ME, Asadi FK. A prospective study of acute renal failure in the newborn infant. Pediatrics. 1979;63:475

10. Agras PL, Tarcan A, Baskin E, Cengiz N, Gurakan $B$, Saatci U. Acute renal failure in the neonatal period. Renal Failure 2004;26:305-309

11. Ringer S A. Acute Renal Failure in Newborn. NeoReviews 2010;11; e243-e251

12. Basu P, Som S, Das H, Choudhuri N. Electrolyte Status in Birth Asphyxia. Indian $J$ Pediatr 2010;77(3):259-62.

13. Anne R. Hansen,Janet S. Soul:Perinatal Asphyxia and Hypoxic Ischaemic Encephalopathy, In Manual of Neonatal Care; Wolters Kluwer Lippincott Williams \& Wilkins, $7^{\text {th }}$ edition2012; chapter 55:716717

14. Aggarwal A, Kumar P,Chowdhary G,Majumdar $S$, Narang A. Evaluation of renal functions in asphyxiated newborns. Trop Pediatr 2005;51:295299.

15. Jayashree G, Dutta AK, Sarna MS, Saili A. Acute renal failure in asphyxiated newborns. Indian Pediatr 1991;28:19-23. 
16. Gupta BD,Sharma P,Bagla J,Parakh M,Soni JP; Renal failure in asphyxiated neonates. Indian Pediatr 2005;42:928-34.

17. López Domínquez O, Rodríquez-Alarcón Gómez J, Oliveros Pérez R, MartínVarqas L, Linares Uribe A, Cotero Lavin A; Acute renal failure in perinatal asphyxia. An Esp Pediatr 1983;19:475-80.

18. Itoo B A, Zakaria M. Al-Hawsawi, Khan A H. Hypoxic ischemic encephalopathy, Incidence and risk factors in North Western Saudi Arabia. Saudi Med J 2003; 24

19. Karlowicz M G, Adelman R D.Nonoliguric and oliguric renal failure in asphyxiated term neonates. Pediatr Nephrol 1995; 9: 718-722.

20. Pejović B, Peco-Antić A, Dunjić R. Acute oliguric renal failure in hypoxic neonates born at full term. Srp Arh Celok Lek 2002; 130: 367-70.

21. Olavarría F, Krause S, Barranco L,Herrmann F, Paez V,Mezzano S, Leal N,López M. Renal Function in
Full-Term Newborns Following Neonatal Asphyxia. Clinical Pediatr 1987;26:334-338.

22. Bourchier D. Birth asphyxia associated oliguria: relationship to outcome at 1 year. $J$ Paediatr Child Health 1991;27:302-3.

23. Perlman JM, Tack ED. Renal injury in the asphyxiated newborn infant: relationship to neurologic outcome. J Pediatr 1988;113:875-9.

24. Misra PK, Kumar A, Natu SM, Kapoor RK, Srivastava KL, Das K. Renal failure in symptomatic perinatal asphyxia. Indian Pediatr 1991;28:1147-51.

25. Kaur S, Jain S, Saba A, Chawla D, Parmar VR, Basu S, et al. Evaluation of glomerular and tubular renal function in neonates with birth asphyxia. Ann trop Peadiatr 2011;31(2):129-34.

26. Verma $V$ et al. Study Basic Biochemical and Haematological Parameters in Perinatal Asphyxia and Its Correlation with Hypoxic Ischaemic Encephalopathy (HIE) Staging. JARBS 2011; 3(2): 79-85. 